\title{
Mutation pattern of KRAS and BRAF oncogenes in colorectal cancer patients
}

\author{
I. RAKO ${ }^{1, *}$, J. JAKIC-RAZUMOVIC ${ }^{2}$, D. KATALINIC ${ }^{3}$, J. SERTIC ${ }^{1}$, S. PLESTINA ${ }^{3}$ \\ ${ }^{1}$ Department of Laboratory Diagnostics, Division of Molecular Diagnostics, University Hospital Center Zagreb, Croatia; ${ }^{2}$ Department of Pathol- \\ ogy and Cytology, University Hospital Center Zagreb, Croatia; ${ }^{3}$ Department of Oncology, Division of Medical Oncology, University Hospital \\ Center Zagreb, Croatia \\ ${ }^{*}$ Correspondence: irako@kbc-zagreb.hr
}

Received August 8, 2011 / Accepted January 17, 2012

\begin{abstract}
The aim of this study was to identify KRAS and $B R A F$ gene mutations in colorectal cancer patients and to assess whether they are linked with clinicopathological features. The results of KRAS and BRAF mutation analysis could be used in the selection of patients for anti-EGFR therapy. All specimens were obtained during routine surgery of patients with colorectal carcinoma. The diagnoses were established by standard procedures and confirmed histopathologically. After DNA extraction, KRAS mutations were analyzed using quantitative real-time PCR and BRAF mutations were analyzed using real-time PCR by fluorescence melting curve analysis. Our results show that KRAS gene mutations were detected in $35.6 \%$ samples and the most frequent mutation was Gly12Val. BRAF gene mutation Val600Glu was detected in $8.5 \%$ samples. Statistical analysis revealed a significant association between the KRAS mutation and Dukes' stage ( $\mathrm{p}=0.034)$, with the lowest frequency in Dukes'A, and between the KRAS mutation and histological grade ( $\mathrm{p}=0.044$ ), with no KRAS mutation found in poor differentiated tumors. The first data about KRAS and BRAF mutational status in the sample of Croatian population with colorectal cancer shows that the incidence of KRAS and BRAF mutations is within generally valid limits. Prospective studies are to be continued in order to determine whether these mutations contribute to progression of colorectal cancer.
\end{abstract}

Key words: colorectal cancer, KRAS, BRAF

Colorectal cancer (CRC) is one of the most common forms of malignant neoplasia and frequently takes a fatal course following metastasis (1). The development of CRC is a multistep process which involves successive genetic alterations (2). Mutations of the genes encoding the Kirsten rat sarcoma viral oncogene homologue (KRAS) and the $\mathrm{v}$-raf murine sarcoma viral oncogene homolog B1 (BRAF) have been implicated in colorectal carcinogenesis (3). Their products mediate cellular responses through RAS/ RAF/MAP kinase signal pathway. Activating mutations of these oncogenes are point mutations (missense mutations) and they arise early during the development of colorectal cancer (3). KRAS gene mutations have been detected in $30-40 \%$ of all patients with CRC and have been linked to poor outcomes. BRAF gene mutations have been detected in $5-15 \%$ of CRCs, but KRAS and BRAF mutations appear to be mutually exclusive $(4,5,6)$.

The epidermal growth factor receptor (EGFR), a tyrosine kinase receptor belonging to the ErbB family, has been found to play a significant role in the pathogenesis of CRC by inducing downstream signaling pathways, such as the phosphatidylinositol-3-kinase/Akt and RAS/RAF/MAP-activated protein kinase (MAPK) pathways, which are crucial in the regulation of cell growth, proliferation, migration, angiogenesis, invasion and apoptosis (7). The EGFR signaling pathway is overexpressed in about $80 \%$ of CRCs and has been the focus of a new drug development (8). Consequently, antibodies targeting EGFR, such as cetuximab and panitumumab, have been examined for therapeutic efficacy in CRC patients (9). Initial evaluation of these new drugs as monotherapy in patients with EGFR-expressing chemotherapy-refractory tumors yielded response rates of approximately $10 \%(10-13)$. The realization that detection of positive EGFR expression by immunostaining does not reliably predict clinical outcome of EGFR-targeted treatment has led to an intense search for alternative predictive biomarkers. Oncogenic activation of signaling pathways downstream of the EGFR, such as mutation of KRAS or 
$B R A F$, is important for the progression of colorectal cancer (14). Tumor KRAS mutations have emerged as an important predictive marker of resistance to panitumumab or cetuximab treatment $(5,15,16)$. Seven different somatic missense mutations in codons 12 and 13 are relevant for therapeutic efficacy of anti-EGFR therapy (5). In addition, among colorectal tumors carrying wild-type KRAS, mutation of $B R A F$ or PIK3CA or loss of PTEN expression may be associated with resistance to EGFR-targeted monoclonal antibody treatment, although these additional biomarkers require further validation before incorporation into clinical practice (10). The activating mutations in KRAS oncogene are found mostly in codons 12 i 13 (>90\%) but also affect codons 61 and $146(17,18)$. The most frequently observed types of mutations are $\mathrm{G}>\mathrm{A}$ transitions, $\mathrm{G}>\mathrm{T}$ and $\mathrm{G}>\mathrm{C}$ transversions (19). Identification of somatic-activating mutations of $B R A F$ has been reported in various cancers, with by far the most common mutation being a $1799 \mathrm{~T}>\mathrm{A}$ transversion leading to a Val600Glu (V600E) substitution (4). Until KRAS mutation is accepted, $B R A F$ is still evolving as a powerful predictive biomarker for anti-EGFR therapy in CRC (20).

Although the role of KRAS in the pathogenesis and progression of CRC is widely accepted, there is no agreement on independent prognostic role of KRAS and BRAF oncogenes in CRC. With the aim to investigate their role in progression of CRC, the incidence of KRAS and BRAF mutations was established in a population of patients with CRC in Croatia and compared with clinicopathological features of tumors and patients.

\section{Materials and methods}

Tumor samples. Tissue specimens from 75 colorectal cancers were obtained from patients who underwent curative surgical resection. All specimens were paraffin embedded and stored in the archive. The patient group consisted of 29 women and 46 men aged $18-80$ years (mean $=60.2$ ). Informed consent was obtained from patients and the study was performed in conformance with the Declaration of Helsinki ethical guidelines. Data on tumor size were not available for two patients, histological grade and Dukes' stage for one patient each. The presence of KRAS gene mutations was not known in two patients, and of $B R A F$ gene mutations in another four patients. For 74 tumor samples, clinocopathological features were as follows: $13.5 \%$ (10/74) tumors were classified as Dukes' A, 23\% (17/74) as Dukes'B and 63.5\% (47/74) tumors as Dukes' C. The majority of tumors (67/74) were classified as well/moderately differentiated (low histological grade) while seven were poorly differentiated tumors (high histological grade). Overall, tumor size ranged from 10 to $110 \mathrm{~mm}$ and $28.8 \%$ (21/73) tumors were larger than $5 \mathrm{~cm}$. (Table 1)

Mutation analysis. Mutational analysis for seven common somatic KRAS mutations and one BRAF point mutation was performed on 75 samples. DNA was extracted using the Qiagen QIAamp FFPE Tissue Kit (Qiagen GmbH, Germany)
Table 1. Clinical features of the sample

\begin{tabular}{llc}
\hline Feature & & Total sample \\
\hline $\begin{array}{l}\text { Age (years) } \\
\text { (means+/-d.f.) }\end{array}$ & & $60.24+/-11.74$ \\
Gender & Male & $46(61.3)$ \\
N(percent) & Female & $29(38.7)$ \\
Tumor size & $\leq 5$ & $52(71.2)$ \\
N(percent) & $>5$ & $21(28.8)$ \\
Histological grade (differentiation) & Well/moderate & $67(90.5)$ \\
N(percent) & Poor & $7(9.5)$ \\
Dukes' stage & $\mathrm{A}$ & $10(13.5)$ \\
N(percent) & B & $17(23.0)$ \\
& $\mathrm{C}$ & $47(63.5)$ \\
\hline
\end{tabular}

following the manufacturer's instructions. The specimen amounts used for extraction were four to six $10-\mu \mathrm{m}$ sections of formalin-fixed, paraffin-embedded tumor samples. After DNA extraction, we used 200-500 ng tumor DNA per reaction, depending on the available amount of the tumor tissue. Mutant KRAS was detected on instrument Roche LightCycler 480 Real-Time PCR System using KRAS Mutation Kit (TheraScreen ${ }^{\circledR}$ KRAS Mutation Kit CE-IVD, DxS, $U K)$ that identifies seven common somatic point mutations located in exon 2 (codons 12 and 13): Gly12Asp, Gly12Ala, Gly12Val, Gly12Ser, Gly12Arg, Gly12Cys and Gly13Asp, using quantitative real-time polymerase chain reaction $(\mathrm{Q}-$ RT-PCR) with allele-specific primers (ARMS and Scorpions technology, ARMS/S)). Eight assays are supplied: the control assay used to asses the total DNA in a sample, and seven mutation assays used to detect the mutant DNA. Each assay is able to detect $1 \%$ mutation in the background of wild-type DNA. A central laboratory (HistoGeneX, Antwerp, Belgium) validated the assay for analytic and diagnostic performance, established acceptance criteria, and included appropriate quality controls for each assay. This method uses absolute quantification as a technique which enables us to quantify a single target sequence and express the final result as an absolute value ( $1 \% \Delta \mathrm{Ct}$ value for the assay) (Figures 1 and $2)$. It is established having very high sensitivity (1\% mutant/ wild-type ratio) and specificity of ARMS/S method.

Mutation in exon 15 of the BRAF gene were detected on instrument Roche LightCycler ${ }^{\circ}$ 2.0 Real-Time PCR using realtime PCR and fluorescence melting curve analysis (FMCA). All primers, probes and positive control for the most frequent $B R A F$ somatic mutation Val600Glu (V600E) were purchased from TIBMolbiol (LightMix ${ }^{\circledR}$ KitBRAF V600E, Germany). Amplification was performed in glass $20-\mu \mathrm{l}$ capillaries containing Roche LightCycler Fast Start DNA Master Hybridization Probes Kit (Roche Diagnostics). Fluorescence melting peaks were obtained by plotting the negative derivative of fluorescent signal corresponding to the temperature (-dF/dT). A melting peak at $61^{\circ} \mathrm{C}$ indicates the presence of the BRAF V600E mu- 


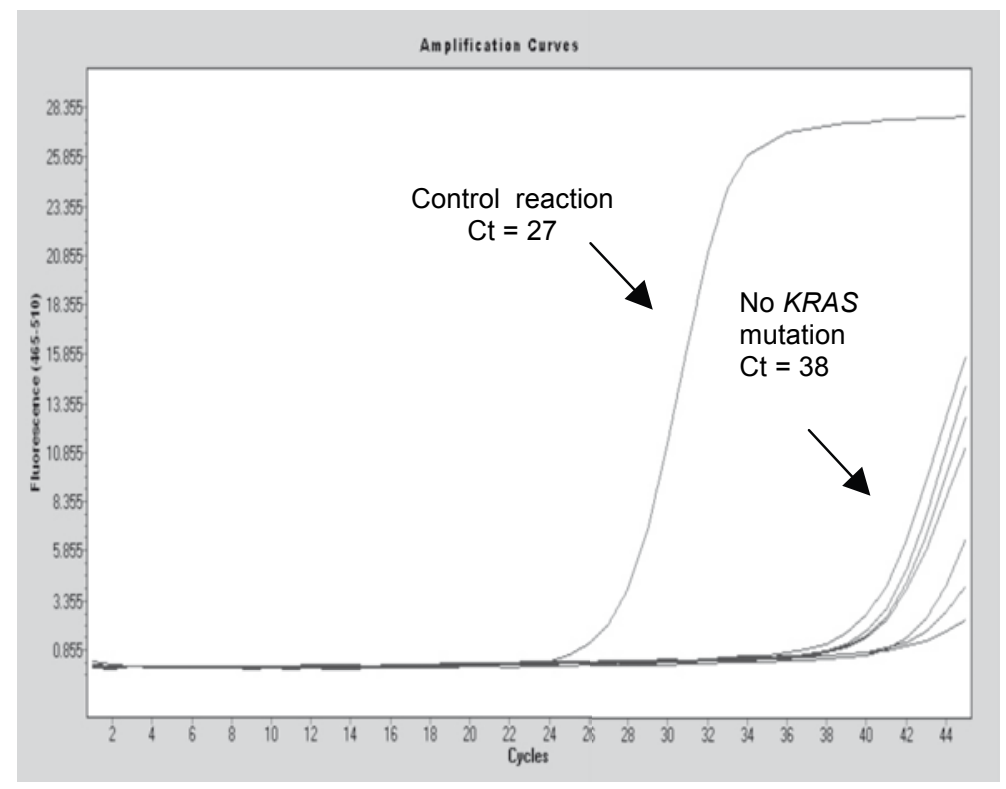

$\mathrm{Ct}=$ cycle threshold; $\Delta \mathrm{Ct}=11>1 \%>\Delta \mathrm{Ct}$

Figure 1. Q-RT-PCR: Negative result for KRAS mutation

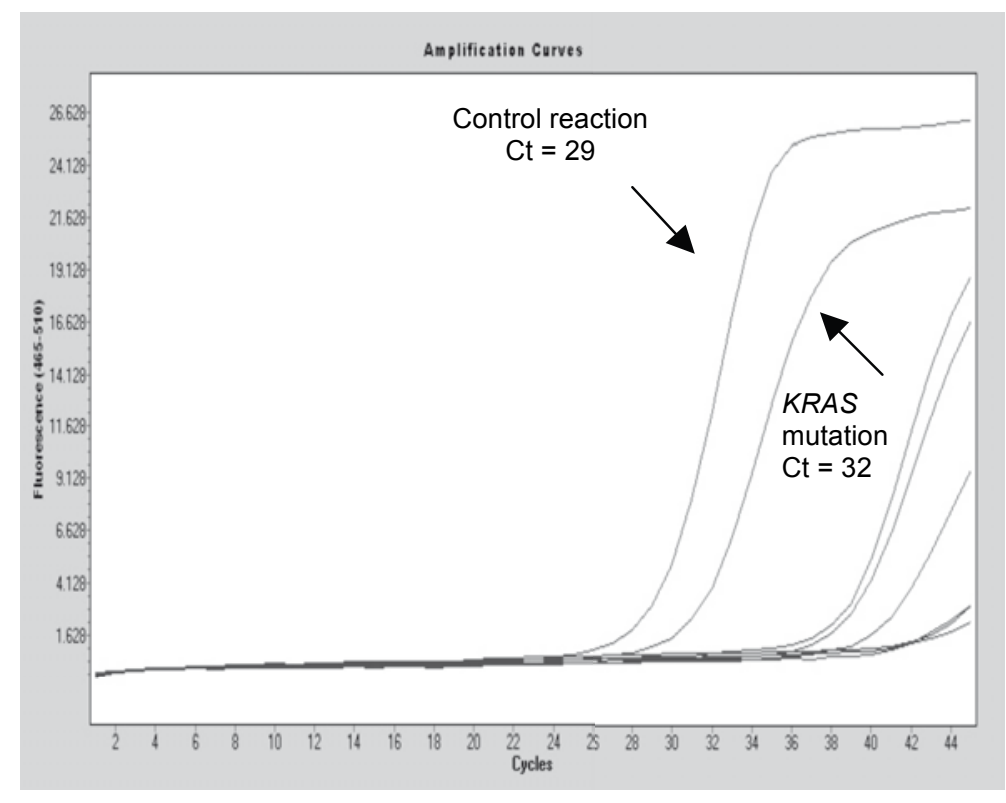

$\mathrm{Ct}=$ cycle treshold; $\Delta \mathrm{Ct}=3<1 \% \Delta \mathrm{Ct}$

Figure 2. Q-RT-PCR: Positive result for KRAS mutation Gly12Val

tated genotype while wild-type samples generate a baseline result or display a peak at $53^{\circ} \mathrm{C}$ due to incomplete supression of the wild-type DNA (Figure 3). As a negative control, we used healtly colorectal mucosa. The observed sensitivity of LightMix BRAF V600E Kit is $0.2 \%$ mutants of BRAF V600E DNA since amplification of the wild-type DNA is suppressed by a competitor.
Statistical analysis. We used descriptive statistics for clinical data presentation. Differences in clinical and pathological variables between the groups of patients with and without $B R A F$ and KRAS mutations were analyzed using $\mathrm{t}$-tests for independent samples for continuous variables and Fisher exact tests for categorical variables, as appropriate. Statistical analysis was performed using SPSS version 13.0. 


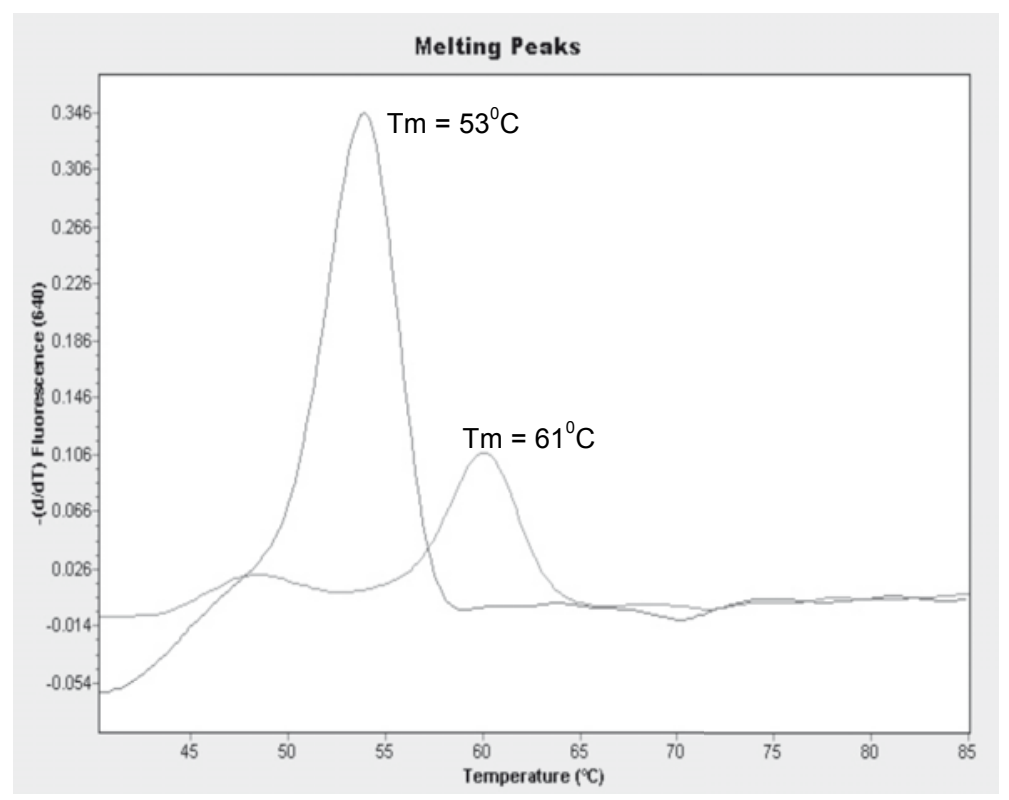

$\mathrm{Tm}=$ melting temperature; negative result $\mathrm{Tm}=53^{\circ} \mathrm{C}$ (negative control, healtly colorectal mucosa), positive result $\mathrm{Tm}=61^{\circ} \mathrm{C}$ (tumor tissue)

Figure 3. FMCA: Negative and positive result for $B R A F$ Val600Glu mutation

\section{Results}

Our results of mutational analysis show that KRAS gene mutations are detected in 26/73 samples (35.6\%) while BRAF gene mutations were comparatively rare events detected in 6/71 samples $(8.5 \%)$.

The most frequent KRAS mutation is Gly12 Val (GGT $>$ GTT) detected in 12 samples (46.1\%). Seven patients had Gly12Asp

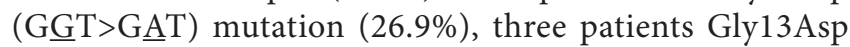

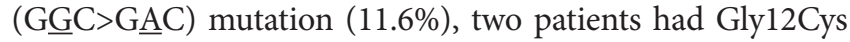
( $\underline{G} \mathrm{TT}>\underline{\mathrm{TGT}}$ ) mutation (7.7\%) and two patients had Gly12Ser (GGT $>\underline{A G T)}$ mutation (7.7\%). Consistent with literature reports, the majority of KRAS mutations were found in codon 12 , with a smaller number of nucleotide substitutions in codon 13. KRAS gene alterations consisted of 14 transversions $(\mathrm{G}>\mathrm{T})$ and 12 transitions $(\mathrm{G}>\mathrm{A})$, out of which twenty three mutations affected codon 12 and three mutations affected codon 13 (Table 2). Statistical analysis revealed a significant association between the KRAS mutation and Dukes' stage $(\mathrm{p}=0.034)$, with the lowest frequency in Dukes' A, and between the KRAS mutation and histological grade $(\mathrm{p}=0.044)$, with no KRAS mutation found in poor differentiated tumors. We found no association between mutations and other clinicopathological features (Table 3).

$B R A F$ gene mutation Val600Glu was detected in 6 samples (8.5\%). All mutations were detected in tumors classified as Dukes' C. Five of six BRAF positive samples (83\%) were well to moderately differentiated tumors in men, one half of positive samples were smaller and half larger than $5 \mathrm{~cm}$. All BRAF mutations were found in tumors with wild-type status of KRAS gene. We found no association between $B R A F$ mutations and clinicopathological features (Table 4).

\section{Discussion}

Mutations in the KRAS and BRAF oncogenes are thought to occur at an early stage in the adenoma-carcinoma sequence, with the frequency of mutations increasing with the tumor size (3). Specific KRAS mutations induce different

Table 2. The number and type of KRAS mutations, affected codons and corresponding altered amino acids

\begin{tabular}{|c|c|c|c|c|c|}
\hline Codon & Type of point mutation & Number of point mutations & Wild-type codon (amino acid) & Mutated codon (amino-acid) & Putative altered amino-acid \\
\hline \multirow[t]{2}{*}{12} & $\mathrm{G}>\mathrm{A}$ & $9(35 \%)$ & GGT (Gly) & GAT (Asp) & $7(27 \%)$ \\
\hline & & & $\underline{\text { GGT (Gly) }}$ & $\underline{\mathrm{A} G T}($ Ser) & $2(8 \%)$ \\
\hline \multirow[t]{2}{*}{12} & $\mathrm{G}>\mathrm{T}$ & $14(54 \%)$ & GG T (Gly) & GTT (Val) & $12(46 \%)$ \\
\hline & & & $\underline{\text { GGT (Gly) }}$ & $\underline{\text { TGT (Cys) }}$ & $2(8 \%)$ \\
\hline 13 & $\mathrm{G}>\mathrm{A}$ & $3(11 \%)$ & GGC (Gly) & GAC (Asp) & $3(11 \%)$ \\
\hline
\end{tabular}


Table 3. Associations between KRAS mutation and clinicopathological features of colorectal cancer

\begin{tabular}{|c|c|c|c|c|}
\hline Feature & & KRAS (wild type) & KRAS (mutation) & Test \\
\hline $\begin{array}{l}{ }^{*} \text { Age }(\text { years }) \\
\text { (means+/-d.f.) }\end{array}$ & & $60.67+/-10.31$ & $59.29+/-14.33$ & $\begin{array}{l}\mathrm{t}=0.477, \\
\mathrm{df}=71, \\
\mathrm{p}=0.635\end{array}$ \\
\hline \multirow[t]{2}{*}{ +Gender N(percent) } & Male & $29(63.0)$ & $16(59.3)$ & $\mathrm{p}=0.806$ \\
\hline & Female & $17(37.0)$ & $11(40.7)$ & \\
\hline \multirow[t]{2}{*}{ +Tumor size $\mathrm{N}$ (percent) } & $\leq 5$ & $29(63.0)$ & $21(84.0)$ & $\mathrm{p}=0.101$ \\
\hline & $>5$ & $17(37.0)$ & $4(16.0)$ & \\
\hline \multirow[t]{2}{*}{ +Histological grade $\mathrm{N}$ (percent) (differentiation) } & Well/moderate & $39(84.8)$ & $26(100)$ & $\mathrm{p}=0.044$ \\
\hline & Poor & $7(15.2$ & $0(0)$ & \\
\hline \multirow[t]{3}{*}{ +Dukes' stage N(percent) } & A & $4(8.7)$ & $4(15.4)$ & $\mathrm{p}=0.034$ \\
\hline & B & $7(15.2)$ & $10(38.5)$ & \\
\hline & $\mathrm{C}$ & $35(76.1)$ & $12(46.1)$ & \\
\hline
\end{tabular}

${ }^{*}$ Data were calculated using two-tailed $\mathrm{t}$ test for independent samples;

+ Data were calculated using fisher exact test for categorical variables

Table 4. Associations between BRAF mutation and clinicopathological features of colorectal cancer

\begin{tabular}{|c|c|c|c|c|}
\hline Feature & & BRAF (wild type) & BRAF (mutation) & Test \\
\hline $\begin{array}{l}\text { *Age (years) } \\
\text { (means+/-d.f.) }\end{array}$ & & $60.25+/-12.06$ & $\begin{array}{l}61.5+/- \\
7.53\end{array}$ & $\begin{array}{l}\mathrm{t}=0.248, \\
\mathrm{df}=69, \\
\mathrm{p}=0.804\end{array}$ \\
\hline \multirow[t]{2}{*}{ +Gender N(percent) } & Male & $40(61.5)$ & $5(83.3)$ & $\mathrm{p}=0.404$ \\
\hline & Female & $25(38.5)$ & $1(16.7)$ & \\
\hline \multirow[t]{2}{*}{ +Tumor size N(percent) } & $\leq 5$ & $47(87.0)$ & $3(50.0)$ & $\mathrm{p}=0.343$ \\
\hline & $>5$ & $17(13.0)$ & $3(50.0)$ & \\
\hline \multirow[t]{2}{*}{ +Histological grade N(percent) (differentiation) } & Well/moderate & $60(92.3)$ & $5(83.3)$ & $\mathrm{p}=0.423$ \\
\hline & Poor & $5(7.7)$ & $1(16.7)$ & \\
\hline \multirow[t]{3}{*}{ +Dukes' stage N(percent) } & A & $10(15.4)$ & $0(0)$ & \\
\hline & B & $17(26.2)$ & $0(0)$ & $\mathrm{p}=0.134$ \\
\hline & $\mathrm{C}$ & $38(58.4)$ & $6(100)$ & \\
\hline
\end{tabular}

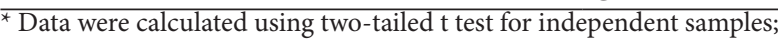

+ Data were calculated using fisher exact test for categorical variables

biological consequences by affecting differently the structural conformation and the function of the mutated protein (21). In particular, disease-free survival of CRC patients and overall survival were shown to depend on the type of KRAS mutation (15). In CRC, about 3000 point mutations (missense mutations) of the KRAS gene have been identified, with predominance in codons 12 and $13(17,22)$. Approximately $90 \%$ of the activating mutations were found in codons 12 (wild-type GGT) and 13 (wild-type GGC), identifying these codons as hot spot mutation points. These two codons, coding for the two adjacent glycine residues, play an important role in the catalytic activity of KRAS proteins. The substitutions of 12 and 13 amino acid residues (Gly) in the KRAS protein with any other amino acid (except prolin) altered its GTP-ase activity to a different extent and/or its ability to interact with its regulators, depending on the substituted amino acid residue (23). The KRAS mutations can be detected in approximately $30-40 \%$ of all patients with colorectal cancer. The most frequently observed types of mutations among the point mutations in human cancers are
$\mathrm{C}>\mathrm{T}$ and $\mathrm{G}>\mathrm{A}$ transitions (24). These $\mathrm{G}>\mathrm{A}$ transition mutations occurred either by misreplication of the unrepaired, endogenously produced $\mathrm{O}^{6}$-methylguanidine from faulty S-adenosylmethionine methylation or due to exposure to nitrosamines (25-27). It was shown that KRAS G>C and $\mathrm{G}>\mathrm{T}$ transversions in CRC were related to worse prognosis than $\mathrm{G}>\mathrm{A}$ transitions (28).

In our study, we found a KRAS mutation in $35.6 \%(26 / 73)$ samples of colorectal cancer: $88 \%$ in codon 12 and $12 \%$ in codon 13. These results are consistent with reported results about frequency of KRAS mutations in CRC where the majority of KRAS mutations were found in codon 12. Among mutations in codon 13, the glycine to aspartate mutation was the most common and accounted for over $80 \%$ of the changes that occur in this codon. We found three glycine to aspartate mutations in codon 13. Most of the mutations that were identified in this study are substitutions of amino acid glycine with valine $46.1 \%(12 / 26)$. This substitution was reported as the second most frequent codon 12 mutation $(22.5 \%)$ and also, connected with increased risk of recur- 
rence and death (29). We did not find Gly12Val mutation in tumors classified as Dukes' A. Among mutations in codon 12, the substitution of glycine with aspartate has been reported as the most frequent change $(32.5 \%)$, but in our study we ranged Gly12Asp only as the second most frequent mutation $26.9 \%(7 / 26)$.

Furthermore, the rate of transversions $(\mathrm{G}>\mathrm{T})$ in our study was found to be $54 \%(14 / 26)$ and of transitions (G>A) $46 \%$ $(12 / 26)$, which is consistent with an observation that these are the most frequently observed types of mutations in CRC (30).

The gold standard for prognostication is clinicopathological staging or Dukes' stage but tumor grade and size have also been established as prognostic factors in CRC $(31,32)$. We found a significant association between the KRAS mutation and Dukes' stage ( $\mathrm{p}=0.034)$ and between the KRAS mutation and histological grade $(\mathrm{p}=0.044)$. The lowest frequency of KRAS mutations was found in Dukes' A and no KRAS mutation found in poor differentiated tumors. We found no association between KRAS mutations and other clinicopathological features. A number of studies published in the past 20 years have produced different results regarding the association between KRAS mutations and prognosis in CRC. Some studies have demonstrated significant differences between KRAS mutations in general or specific types of KRAS mutations and tumor stage, grade, survival and/or other clinocopathological variables, whereas others have not $(15,33)$. The small sample size of several studies and the different methods used to detect mutations might be the basis of the discordant conclusions reachd by these investigations.

In the present study, mutations in $B R A F$ were identified in $8.5 \%(6 / 71)$ of colorectal cancers and they never occurred in association with KRAS mutation. Tumors with detected $B R A F$ V600E mutation were classified as Dukes' C. All these data are consistent with reported results which suggest that KRAS and $B R A F$ mutations are two different epigenetic alterations among CRCs, mutually exclusive, with possible negative prognostic role in this disease (34).

High sensitivity (1\% mutant/wild-type ratio) and specificity of ARMS/S method enable us to detect the presence of KRAS mutation in heterogeneous specimens at a low allelic concentration without the need for confirmation by direct sequencing $(35,36)$. For detection of BRAF V600E mutation the melting curve analysis was previously described indicating the melting temperature for wild type $B R A F$ at $53^{\circ} \mathrm{C}$, whereas the V600E mutant melted at $61^{\circ} \mathrm{C}$ (37). The LightCycler PCR and post-PCR melting curve analysis method for detection of $B R A F$ V600E mutation with TIBMolbiol primers and probes was validated and considered a sensitive method which can be used for diagnostic purposes (38). The observed sensitivity of LightMix BRAF V600E Kit is $0.2 \%$ mutants of BRAF V600E DNA since amplification of the wild-type DNA is suppressed by competitor and was used in the recent updated analysis of overall survival according to tumor KRAS and $B R A F$ mutation status in colorectal cancer (39).
According to recent statistics of World Health Organization, Croatia is taking the first place in the world against mortality of colorectal cancer and, because of the low rates of screening, only small number of cases are diagnosed in localized stage of this disease. As our set of colorectal cancer tissue samples was obtained from patients who underwent curative surgical resection in University Hospital Center Zagreb (year 2009/10.), we observed only small percent of tumor samples classified as Dukes'A .

This is the first study about incidence of KRAS and $B R A F$ gene mutations in colorectal cancer of Croatian patients. Our data on KRAS and BRAF mutational status in the studied sample of colorectal cancer shows that the incidence of KRAS (35.6\%) and $B R A F(8.5 \%)$ mutations is within commonly accepted limits of $30-40 \%$ and $5-15 \%$, respectively. Significant association between the KRAS mutations and Dukes' stage was found and suggests that the presence of these mutations may play a role in the progression of this disease in our group of patients. However, significantly higher incidence of mutation in well/moderate differentiated tumours opposes to this findings (considering the small number of poor differentiated tumours in the overall study sample). These data should be confirmed on a larger study group in prospective studies in order to determine whether these mutations contribute to progression of CRC. All obtained results could serve in selection of patients for anti-EGFR monoclonal antibody therapy and as predictive biomarkers of responsiveness to the same therapy.

Acknowledgements: This study has been carried out as part of Project No. 108-1080058-0047, Croatian Ministry of Science, Education and Sports.

\section{References}

[1] JEMAL A, SIEGEL R, WARD E, MURRAY T, XU J et al. Cancer statistics, 2007 CA. A Cancer Journal for Clinicians 2007; 57: 43-66. http: //dx.doi.org/10.3322/canjclin.57.1.43

[2] FEARON ER, VOGELSTEIN B. A genetic model for colorectal tumorigenesis. Cell 1990; 61: 759-67. http: //dx.doi. org/10.1016/0092-8674(90)90186-I

[3] JONES S, CHEN W, PARMIGIANI G, DIEHL F, BEERENWINKEL $\mathrm{N}$ et al. Comparative lesion sequencing provides insights into tumor evolution. PNAS 2008; 105; 11; 4283-8. http: //dx.doi.org/10.1073/pnas.0712345105

[4] DAVIES H, BIGNELL GR, COX C, STEPHENS P, EDKINS $S$ et al. Mutations of the BRAF gene in human cancer. Nature 2002; 417; 949-954. http: //dx.doi.org/10.1038/nature00766

[5] RUSSO A, BAZAN V, AGNESE V, RODOLICO V, GEBBIA $N$. Prognostic and predictive factors in colorectal cancer: Kirsten Ras in CRC (RASCAL) and TP53CRC collaborative studies. Annals of Oncology 2005; 16 iv44-iv49. http: //dx.doi. org/10.1093/annonc/mdi907

[6] GATTENLOHNER S, ETSCHMANN B, KUNZMANN V, THALHEIMER A, HACK $\mathrm{M}$ et al. Concordance of KRAS/ BRAF mutation status in metastatic colorectal cancer before 
and after Anti-EGFR Therapy. J Oncol 2009; Article ID 831626; 5 .

[7] MONZON FA, OGINO S, HAMMOND ME, HALLING KC, BLOOM KJ et al. The role of KRAS mutation testing in the management of patients with metastatic colorectal cancer. Arch Patol Lab Med 2009; 133; 1600-06.

[8] POREBSKA I, HARLOZINSKA A, BOJAROWSKI T. Expression of the tyrosine kinase activity growth factor receptors (EGFR, ERB B2, ERB B3) in colorectal adenocarcinomas and adenomas. Tumour Biol 2000; 21: 105-15. http: //dx.doi. org/10.1159/000030116

[9] REYNOLDS NA, WAGSTAFF AJ. Cetuximab: in the treatment of metastatic colorectal cancer. Drugs 2004; 64: 109-118.

[10] SIENA S, BIANCHI AS, NICOLANTONIO FD, BALFOUR J, BARDELLI A. Biomarkers predicting clinical outcome of epidermal growth factor receptor-targeted therapy in metastatic colorectal cancer. JNCI 2009; 101: 1308-24. http: //dx.doi. org/10.1093/jnci/djp280

[11] SALTZ LB, MEROPOL NJ, LOEHRER PJ SR, NEEDLE MN, KOPIT J et al. Phase II trial of cetuximab in patients with refractory colorectal cancer that expresses the epidermal growth factor receptor . J Clin Oncol 2004; 22: 1201- 8. http: //dx.doi.org/10.1200/JCO.2004.10.182

[12] JONKER DJ, O'CALLAGHAN CJ, KARAPETIS CS, ZALCBERG JR, TU D et al . Cetuximab for the treatment of colorectal cancer. N Engl J Med 2007; 357: 2040-8. http: //dx.doi.org/10.1056/NEJMoa071834

[13] VAN CUTSEM E, PEETERS M, SIENA S, HUMBLET Y, HENDLISZ A et al . Open-label phase III trial of panitumumab plus best supportive care compared with best supportive care alone in patients with chemotherapy-refractory metastatic colorectal cancer. J Clin Oncol 2007; 25: 1658-64 . http: //dx.doi.org/10.1200/JCO.2006.08.1620

[14] BENVENUTI S, SARTORE-BIANCHI A, DI NICOLANTONIO F, ZANON C, MORONI M et al. Oncogenic activation of the RAS/RAF signaling pathway impairs the response of metastatic colorectal cancers to anti-epidermal growth factor receptor antibody therapies. Cancer Res 2007; 67: 2643-8. http: //dx.doi.org/10.1158/0008-5472. CAN-06-4158

[15] ANDREYEV HJ, NORMAN AR, CUNNINGHAM D, OATES J, DIX BR et al. Kirsten ras mutations in patients with colorectal cancer: the "RASCAL II" study. Br J Cancer 2001; 85: 692-96.

[16] SAMOWITZ WS, CURTIN K, SCHAFFER D, ROBERTSON $\mathrm{M}$, LEPPERT $\mathrm{M}$ et al. Relationship of Ki-ras mutations in colon cancers to tumor location, stage, and survival: a population based study. Cancer Epidemiol Biomarkers Prev 2000; 9: 1193-7.

[17] EDKINS S, O'MEARA S, PARKER A, STEVENS C, REIS M et al. Recurrent KRAS codon 146 mutations in human colorectal cancer. Cancer Biol Ther 2006; 5: 928-32. http: //dx.doi. org/10.4161/cbt.5.8.3251

[18] OLIVEIRA C, WESTRA JL, ARANGO D, OLLIKAINENE M, DOMINGO E et al. Distinct patterns of KRAS mutations in colorectal carcinomas according to germline mismatch repair defects and hMLH1 methylation status. Human Molecular Genetics 2004; 13: 2303-11. http: //dx.doi.org/10.1093/hmg/ $\underline{\operatorname{ddh} 238}$

[19] RISIO M, MALACARNE D, GIARETTI W. Letter to the Editor. KRAS transitions and villous growth in colorectal adenomas. Cell Oncol 2005; 27: 363-6.

[20] DI NICOLANTONIO F, MARTINI M, MOLINARI F, SARTORE-BIANCHI A, ARENA S et al. Wild-type BRAF is required for response to panitumumab or cetuximab in metastatic colorectal cancer. JCO 2008; 26: 5705-12. http: //dx.doi.org/10.1200/JCO.2008.18.0786

[21] AL-MULLA F, MACKENZIE EM. Differences in in vitro invasive capacity induced by differences in Ki-Ras protein mutations. J Pathol 2001; 195: 549-56. http: //dx.doi.org/ 10.1002/path.995

[22] KOSAKA T, YATABE Y, ENDOH H, KUWANO H, TAKAHASHI $\mathrm{T}$ et al. Mutations of the epidermal growth factor receptor gene in lung cancer: biological and clinical implications. Cancer Res 2004; 64: 8919-23. http: //dx.doi. org/10.1158/0008-5472.CAN-04-2818

[23] AL-MUlla F, GOING JJ, SOWDEN ET, WINTER A, PICKFORD IR et al. Heterogeneity of mutant versus wildtype in primary and metastatic colorectal carcinomas and association of codon 12 valine with early mortality. J Pathol 1998; 185: 130-8. http: //dx.doi.org/10.1002/(SICI)10969896(199806)185: 2<130: : AID-PATH85>3.0.CO; 2-M

[24] STENSON PD, BALL EV, MORT M, PHILLIPS AD, SHIEL JA et al. Human Gene Mutation Database (HGMD): 2003 update. Hum Mutat 2003; 21: 577-581. http: //dx.doi.org/10.1002/ humu. 10212

[25] RYDBERG B, LINDAHL T. Nonenzymatic methylation of DNA by the intracellular methyl group donor S-adenosyl-Lmethionin is a potentially mutagenic reaction. EMBO J 1982; 1: 211-6.

[26] LIJINSKY W. N-Nitroso compounds in the diet. Mutat Res 1999; 443: 129-138.

[27] COLE DN, CARLSON JA, WILSON VL. Human Germline and somatic cells have similar TP53 and Kirsten-RAS gene single base mutation frequencies. Environ Mol Mutagen 2008; 49: 417-25. http: //dx.doi.org/10.1002/em.20390

[28] GEIDO E, SCIUTTO A, RUBAGOTTI A, OLIANI C, MONACO R, RISIO M et al. Combined DNA flow cytometry and sorting with k-ras2 mutation spectrum analysis and the prognosis of human sporadic colorectal cancer. Cytometry 2002; 50: 216-24. http: //dx.doi.org/10.1002/cyto.10109

[29] ANDREYEV HJ, NORMAN AR, CUNNINGHAM D, OATES JR, CLARKE PA. Kirsten ras mutations in patients with colorectal cancer: the multicenter "RASCAL" study. J Natl Cancer Inst 1998; 90: 675-84.

[30] UROSEVIC N, KRTOLICA K, SKARO-MILIC A, KNEZEVIC-USAJ S, DUJIC A. Prevalence of G-to-T transversions among K-ras mutations in colorectal tumors in Yugoslavia. Int J Cancer 1993; 54: 249-54. http: //dx.doi.org/10.1002/ ijc. 2910540215

[31] COMPTON CC, FIELDING P, BUGART LJ, CONLEY B, COOPER HS et al. Prognostic factors in colorectal cancer. Arch Patol Lab Med 2000; 124: 979-93. 
[32] WALTHER A, JOHNSTONE E, SWANTON C, MIDGLEY $\mathrm{R}$, TOMLINSON I et al. Genetic prognostic and predictive markers in colorectal cancer. Nature 2009; 9: 489-98.

[33] ANWAR S, FRAYLING IM, SCOTT NA, CARLSON GL. Systematic review of genetic influences on the prognosis of colorectal cancer. British Journal of Surgery 2004; 91: 1275-91. http: //dx.doi.org/10.1002/bjs.4737

[34] TOL J, NAGTEGAAL ID, PUNT CJ. BRAF mutation in metastatic colorectal cancer. N Engl J Med 2009; 361: 98-99. http: //dx.doi.org/10.1056/NEJMc0904160

[35] FRANKLIN WA, HANEY J, SUGITA M, BEMIS L, JIMENO A et al. Comparison of testing methods and tissue sampling techniques in colon cancer. J Mol Diagn 2010; 12: 43-50.

[36] ALLEGRA CJ, JESSUPJM, SOMERFIELD MR, HAMILTON SR, HAMMOND EH et al. American Society of Clinical Oncology Provisional Clinical Opinion: Testing for KRAS gene mutations in patients with metastatic colorectal carcinoma to predict response to Anti-Epidermal Growth Factor Receptor Momoclonal Antibody Therapy.
J Clin Oncol 2009; 27: 2091-6. http: //dx.doi.org/10.1200/ JCO.2009.21.9170

[37] MAESTRO ML, VIDAURRETA M, SANZ-CASLA MT. Role of the BRAF mutations in the microsatellite instability genetic pathway in sporadic colorectal cancer. Ann Surg Oncol 2007; 14: 1229-36. http://dx.doi.org/10.1245/s10434006-9111-z

[38] NIKOFOROVA MN, KIMURA ET, GANDHI M, BIDDINGER PW, KNAUF JA et al. BRAF mutations in thyroid tumors are restricted to papillary carcinomas and anaplastic or poorly differentiated carcinomas arising from papillary carcinomas. J Clin Endo and metabol 2003; 88: 5399-5404.

[39] VAN CUSTEM E, KOHNE CH, LANG I, FOLPRECHT G, NOWACKI MP et al. Cetuximab plus irinotecan, fluorouracil, and leucovorin as first-line treatment for metastatic colorectal cancer: updated analysis of overall survival according to tumor KRAS and BRAF mutation status. J Clin Oncol 2011; 29: 2011-9. http: //dx.doi.org/10.1200/JCO.2010.33.5091 